\title{
Effects of particle size and tapped density on the content uniformity of repaglinide - metformin fixed dose tablet combination
}

\author{
Onur PINARBAŞLI ${ }^{\text {* }}$ (D) , Gülistan Pelin GURBETOĞLU 1 (D), Bahar KÖKSEL ÖZGEN 1 (D), \\ Nagehan SARRAÇOĞLU ${ }^{1}$ (D), Asuman AYBEY DOĞANAY ${ }^{1}$ (D) \\ 1 Ilko Pharmaceuticals, Research and Development Center, Ankara, Turkey. \\ * Corresponding Author. E-mail: opinarbasli@gmail.com (O.P.); Tel. +90-312-248 6800.
}

Received: 11 February 2021 / Revised: 25 February 2021 / Accepted: 27 March 2021

\begin{abstract}
The study proposes a solution to content uniformity problem of repaglinide-metformin $\mathrm{HCl}$ fixed dose tablet combination with optimization of particle size distribution and tapped density of repaglinide and metformin granules. The developed dosage forms contain less than $0.5 \% \mathrm{w} / \mathrm{w}$ repaglinide and more than $75 \% \mathrm{w} / \mathrm{w}$ metformin hydrochloride in the composition, resulting in content uniformity problems. A route for, minimizing susceptibility to segregation during the tablet press operation, thereby improving content uniformity, was studied through adjusting the particle size distribution and tapped density of the granules. In this study, a new specification in manufacturing method was developed for obtaining repaglinide and metformin granules with particle size distribution and tapped density properties optimized for tablet homogeneity. Specific particle size distribution and tapped density specifications between metformin $\mathrm{HCl}$ and repaglinide granules were described as (i) particle size distribution $\left(\mathrm{D}_{90}, \mathrm{D}_{50}\right.$ and $\left.\mathrm{D}_{10}\right)$ of metformin $\mathrm{HCl}$ granule should be less than or equal to three times of particle size distribution ( $\mathrm{D}_{90}, \mathrm{D}_{50}$ and $\left.\mathrm{D}_{10}\right)$ of repaglinide granule; and (ii) tapped density of metformin $\mathrm{HCl}$ granule should be less than or equal to two times of tapped density of repaglinide granule. Assay and in vitro dissolution rate analysis were performed by validated HPLC methods.
\end{abstract}

KEYWORDS: Repaglinide; metformin $\mathrm{HCl}$; fixed dose combination; content uniformity; particle size distribution; tapped density.

\section{INTRODUCTION}

Diabetes mellitus commonly known as diabetes, which is a metabolic disorder characterized by high blood glucose (sugar) levels over a prolonged period, is a compelling global health problem with a large and growing prevalence worldwide and high levels of associated morbidity and mortality. There are different types of diabetes; most common is the type 2 diabetes, also known as non-insulin dependent diabetes (NIDDM), which is caused by the body's inability to use insulin [1].

Metformin is an antihyperglycemic agent that improves glucose tolerance in patients having noninsulin dependent (Type 2) diabetes mellitus, lowering both basal and postprandial plasma glucose. Its pharmacologic mechanism conducted as decreasing hepatic glucose production and intestinal absorption of glucose, and improving insulin sensitivity by increasing peripheral glucose uptake and utilization $[2,3]$.

Repaglinide is a blood glucose-lowering agent of the meglitinide class utilized in the management of type 2 diabetes mellitus. The action of the mechanism is characterized as lowering blood glucose levels by stimulating the release of insulin from the pancreas [4].

Fixed dose combinations (FDCs) provide an important alternative to medications that need to be taken separately. They have four important advantages that directly contribute to improved drug compliance in patients. First, fixed dose combinations provide a method by which the number of drugs to be taken and the dosing/ timing schedule can be made easier, which decrease the frequency of missed doses. Secondly, by using lower doses of the two active agents in fixed combinations, it may provide greater efficacy than that obtained with a higher or maximum dose of a single active agent. Thirdly, since glycemic targets are achieved by using lower doses of the active agents in combination, the risk of side effects that may be more likely to occur with the active agents used in higher monotherapy doses can be avoided. Finally, fixed dose

How to cite this article: Pınarbaşlı O, Gurbetoğlu GP, Köksel Özgen B, Sarraçoğlu N, Aybey Doğanay A. Effects of particle size and tapped density on the content uniformity of repaglinid-metformin fixed dose tablet combination. J Res Pharm. 2021; 25(3): 331-340. 
combinations are generally less costly than taking two active agents separately and offer a financial advantage for patients [5].

In pharmaceutical field, fixed dose combination drug products are commonly used at almost all therapeutic areas. Combination therapy with an anti-hyperglycemic drug, metformin, and an oral hypoglycemic drug, repaglinide, is an acceptable dual-therapy option for type 2 diabetes. Metformin regulates basal glucose levels and repaglinide targets postprandial glucose excursions. The two agents have complementary mechanisms of action and both are agents recommended by AACE/ACE for the management of hyperglycemia in patients with HbA1c levels lower than 9.0\%. According to study conducted by Moses R, et al. (1999), the subjects who are exposed to combination of metformin and repaglinide showed important progress in glycemic control: HbA1c decreased from 8.3 to $6.9 \%$, and FPG decreased from 10.2 to $8.0 \mathrm{mmol} / \mathrm{L}$ which are considered significantly important while comparing with treatment with repaglinide or metformin alone. Entirely, $59 \%$ of patients having type 2 diabetes in the combined therapy group accomplished optimum glycemic control, with $\mathrm{HbA1c} 7.1 \%$ [3, 6, 7].

Reference product of Repaglinide - Metformin $\mathrm{HCl}$ Tablet which is PrandiMet ${ }^{\circledR}$ produced by Novo Nordisk (Bagsværd, Denmark) was approved by the Food and Drug Administration (FDA) in June 2008 with dosage forms of $1 \mathrm{mg} / 500 \mathrm{mg}$ and $2 \mathrm{mg} / 500 \mathrm{mg}$. Repaglinide - Metformin $\mathrm{HCl}$ fixed dose combination tablet is noted as an adjunct to diet and exercise to improve glycemic control in adults with type 2 diabetes mellitus who are now treated with a meglitinide and metformin or who have insufficient glycemic control on either meglitinide or metformin alone [8,9].

In the literature, there are some technical problems in the fixed dose combination repaglinide metformin tablet formulations that need to be overcome. First problem is bad flow property of metformin that causes compressibility problems [10]. Second one is content uniformity problem which is related to low content of one of active substances (repaglinide) in the formulation [11]. Fixed dose combination dosage form containing either $2 \mathrm{mg}$ or $1 \mathrm{mg}$ repaglinide and $500 \mathrm{mg}$ metformin $\mathrm{HCl}$ comprises less than $0.5 \% \mathrm{w} / \mathrm{w}$ of repaglinide and more than $75 \% \mathrm{w} / \mathrm{w}$ of metformin hydrochloride in the composition, resulting in content uniformity problems.

According to pharmacopoeial guidelines, solid dosage forms having low content of the active substance must satisfy specific requirements concerning content uniformity. The content uniformity represents a critical parameter for drug forms particularly in case of active substances with only narrow interval between their active and toxic doses. By keeping the content uniformity in individual dosage units of the drug form, it is being ensured that the patient receives only the effective dose of the active substance and not a toxic one [12].

Therefore, it is a particular challenge to a pharmaceutical scientist to develop the type of formulation as described one active substance, with the low-dose and low-solubility of repaglinide, is being uniformly dispersed in another active substance, the high-dose and highly water-soluble metformin or a salt thereof, where both active substances are eventually released at the desired rate. In addition, having different physical properties causes the mixed granules to have segregation problems during tablet pres. Segregation is an action where a homogeneous mixture of granules with different properties (size, density, shape, etc.) tends to be heterogeneous. In the pharmaceutical industry, it is one of the most important problems that use granular materials in their processes [13]. The effects of particle size or size distribution on the homogeneity of the content have been studied to confirm accordance with the United States Pharmacopoeia Standard [14, 15].

The aim of this study is to develop a tablet formulation with pharmaceutical composition of repaglinide and metformin adjusting the particle size distribution and tapped density of repaglinide and metformin granules to overcome content uniformity problem of repaglinide while providing bioequivalence with the reference product Prandimet ${ }^{\circledR} 2 \mathrm{mg}-500 \mathrm{mg}$ Film Coated Tablets. The important point of this study was to minimize susceptibility to segregation during the tablet press operation, thereby improving content uniformity, with forming optimum particle size distribution and tapped density specifications for prepared granules before preparing final granule mixture.

\section{RESULTS AND DISCUSSION}

\subsection{Analytical method and validation studies}

Validation of analytical HPLC methods, which are the assay and in vitro dissolution test method of the finished product, were completed successfully as to specificity, linearity, stress, precision, accuracy, recovery, and robustness. In the assay method, linearity determination coefficients were higher than $\mathrm{R}^{2}=0.99$ and the recoveries were $101.5 \% \pm 1.15 \%$ for repaglinide and $100.4 \% \pm 1.24 \%$ for metformin in $95 \%$ confidence interval; 
and in the dissolution test method, the corresponding values were higher than $\mathrm{R}^{2}=0.99$ and $102.1 \% \pm 1.52 \%$ for repaglinide and $96.8 \% \pm 0.95 \%$ for metformin in $95 \%$ confidence interval, respectively.

\subsection{Formulation studies}

In this study, two different formulations (Test Formulation - A and Test Formulation - B) were selected from many studies in order to clarify the relations between particle size distribution and tapped density with the content uniformity problem of the drug product. Content uniformity studies were carried out on the experimental batches produced. After the selection of test product having satisfactory content uniformity results, in vitro dissolution studies were conducted to test formulation and reference product in order to compare the dissolution profiles. Finally, bioequivalence studies were conducted to test product and reference product.

\subsection{Content uniformity}

\subsubsection{Content uniformity of the final granule mixture}

Content uniformity results of repaglinide at final granule mixture are given at Table 1. From the experimental data, it is apparent that differences in standard deviation of the final granule mixture are not significant; therefore, homogeneity is not a problem at mixing stage.

\subsubsection{Content uniformity of tablets}

Content uniformity results of repaglinide at drug product are given at Table 1. According to results, it is apparent that differences in standard deviation of the tablets are remarkable; therefore, it is concluded that the problem of content uniformity mainly occurs as segregation of granules during tablet press operation. In order to determine the causes of this problem, particle size distribution and tapped density measurements were performed.

Table 1. Content uniformity results of repaglinid at final granule mixture and drug product $(\mathrm{n}=10)$.

\begin{tabular}{ccccc}
\hline \multirow{2}{*}{ Sample } & \multicolumn{2}{c}{ Final Granule Mixture } & \multicolumn{2}{c}{ Drug Product } \\
\cline { 2 - 5 } & Test Form. - A & Test Form. - B & Test Form. - A & Test Form. - B \\
\hline $\mathbf{1}$ & 102.5 & 101.0 & 109.2 & 99.3 \\
$\mathbf{2}$ & 103.5 & 100.6 & 115.1 & 102.4 \\
$\mathbf{3}$ & 98.5 & 99.8 & 99.4 & 101.0 \\
$\mathbf{4}$ & 106.5 & 100.7 & 108.2 & 102.6 \\
$\mathbf{5}$ & 99.4 & 102.5 & 104.7 & 101.3 \\
$\mathbf{6}$ & 95,4 & 98.9 & 101.6 & 100.8 \\
$\mathbf{7}$ & 102.6 & 99.4 & 116.3 & 98.7 \\
$\mathbf{8}$ & 105.1 & 100.6 & 98.5 & 102.6 \\
$\mathbf{9}$ & 95.6 & 100.4 & 92.0 & 101.3 \\
$\mathbf{1 0}$ & 98.8 & 99.4 & 110.1 & 101.4 \\
Average & $\mathbf{1 0 0 . 8}$ & $\mathbf{1 0 0 . 3}$ & $\mathbf{1 0 5 . 5}$ & $\mathbf{1 0 1 . 1}$ \\
SDa & $\mathbf{3 . 8 3}$ & $\mathbf{1 . 0 3}$ & $\mathbf{7 . 7 1}$ & $\mathbf{1 . 3 1}$ \\
RSD $^{\mathbf{b}}$ \% & $\mathbf{3 . 8 0}$ & $\mathbf{1 . 0 2}$ & $\mathbf{7 . 3 1}$ & $\mathbf{1 . 3 0}$ \\
\hline
\end{tabular}

a Standard deviation.

b Relative standard deviation.

\subsection{Particle size distribution}

The results of particle size distribution for produced Metformin $\mathrm{HCl}$ and Repaglinide granules of two different formulations are given at Table 2 (Particle size distribution profiles are given at Figure 1). In order to have satisfactory content uniformity results, the particle size distribution $\left(\mathrm{D}_{90}\right)$ of metformin granules should be between of 300-800 $\mu \mathrm{m}$, preferably $350-450 \mu \mathrm{m}$ and particle size distribution ( $\mathrm{D}_{90}$ ) of repaglinide granules should be between of 150-400 $\mu \mathrm{m}$, preferably $250-350 \mu \mathrm{m}$. 
Table 2. Particle size distribution results of metformin $\mathrm{HCl}$ and repaglinide granules manufactured separately with fluidized bed spray granulation method (mean $\pm S D, n=6$ ).

\begin{tabular}{|c|c|c|c|}
\hline \multicolumn{4}{|c|}{ Test Formulation - A } \\
\hline & \multicolumn{3}{|c|}{ 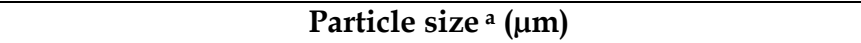 } \\
\hline & $\mathrm{D}_{10}$ & $\mathrm{D}_{50}$ & $\mathrm{D}_{90}$ \\
\hline Metformin $\mathrm{HCl}$ granule (M) & $152.93 \pm 0.50 \mu \mathrm{m}$ & $570.28 \pm 2.56 \mu \mathrm{m}$ & $923.74 \pm 5.73 \mu \mathrm{m}$ \\
\hline Repaglinide granule (R) & $40.05 \pm 0.21 \mu \mathrm{m}$ & $95.68 \pm 1.54 \mu \mathrm{m}$ & $301.80 \pm 4.50 \mu \mathrm{m}$ \\
\hline Ratio (M/R) & 3.82 & 5.96 & 3.06 \\
\hline \multicolumn{4}{|c|}{ Test Formulation - B } \\
\hline & \multicolumn{3}{|c|}{ Particle size $(\mu \mathrm{m})^{\mathrm{a}}$} \\
\hline & $\mathrm{D}_{10}$ & $\mathrm{D}_{50}$ & $\mathrm{D}_{90}$ \\
\hline Metformin $\mathrm{HCl}$ granule (M) & $102.28 \pm 0.86 \mu \mathrm{m}$ & $260.15 \pm 0.51 \mu \mathrm{m}$ & $400.27 \pm 1.28 \mu \mathrm{m}$ \\
\hline Repaglinide granule (R) & $40.05 \pm 0.21 \mu \mathrm{m}$ & $95.68 \pm 1.54 \mu \mathrm{m}$ & $301.80 \pm 4.50 \mu \mathrm{m}$ \\
\hline Ratio (M/R) & 2.55 & 2.72 & 1.33 \\
\hline
\end{tabular}

\subsection{Tapped Density}

Tapped density results of produced metformin $\mathrm{HCl}$ and repaglinide granules of two different formulations are given at Table 3. In order to have satisfactory content uniformity results, the tapped density of metformin granules should be between 0.4 and $0.8 \mathrm{~g} / \mathrm{mL}$, and repaglinide granule should be between of 0.3 and $0.6 \mathrm{~g} / \mathrm{mL}$.

Table 3. Tapped density results of metformin and repaglinide granules manufactured separately with fluidized bed spray granulation method (mean \pm SD, $n=3$ ).

\begin{tabular}{lc}
\hline \multicolumn{2}{c}{ Test Formulation - A } \\
\hline & Tapped density $(\mathrm{g} / \mathrm{mL})$ \\
Metformin HCl granule (M) & $0.92 \pm 0.06$ \\
Repaglinide granule (R) & $0.42 \pm 0.05$ \\
Ratio (M/R) & $\mathbf{2 . 1 9}$ \\
\hline \multicolumn{2}{c}{ Test Formulation - B } \\
\hline \multicolumn{2}{c}{ Tapped density (g/mL) } \\
Metformin HCl granule (M) & $0.57 \pm 0.02$ \\
Repaglinide granule (R) & $0.42 \pm 0.05$ \\
Ratio (M/R) & $\mathbf{1 . 3 6}$ \\
\hline
\end{tabular}

According to results for content uniformity of drug product given at Table 2, tablets prepared with Test formulation - B have satisfactory content uniformity results with low standard deviation. In the lights of the obtained results, the following particle size distribution and tapped density specifications were determined.

- Particle size distribution specifications between metformin $\mathrm{HCl}$ and repaglinide granules are described below:

(1) Particle size distribution $\left(\mathrm{D}_{90}\right)$ of metformin $\mathrm{HCl}$ granule should be less than or equal to three times of particle size distribution $\left(\mathrm{D}_{90}\right)$ of repaglinide granule,

(2) Particle size distribution $\left(\mathrm{D}_{50}\right)$ of metformin $\mathrm{HCl}$ granule should be less than or equal to three times of particle size distribution $\left(\mathrm{D}_{50}\right)$ of repaglinide granule

(3) Particle size distribution $\left(\mathrm{D}_{10}\right)$ of metformin $\mathrm{HCl}$ granule should be less than or equal to three times of particle size distribution $\left(\mathrm{D}_{10}\right)$ of repaglinide granule.

- Tapped density specification between metformin $\mathrm{HCl}$ and repaglinide granules is described below:

(1) Tapped density of metformin $\mathrm{HCl}$ granule should be less than or equal to two times of tapped density of repaglinide granule.

According to results given above, granules obtained by Test formulation - B are ensured particle size distribution and tapped density specifications, but granules obtained by Test formulation - A are not; particle size $\left(\mathrm{D}_{90}\right)$ distribution of metformin granule is 3.10 times to repaglinide granule and tapped density of metformin granule is 2.19 times to repaglinide granule. Consequently, tablets prepared by Test formulation A have unsatisfactory content uniformity results which are given in Table 2. 

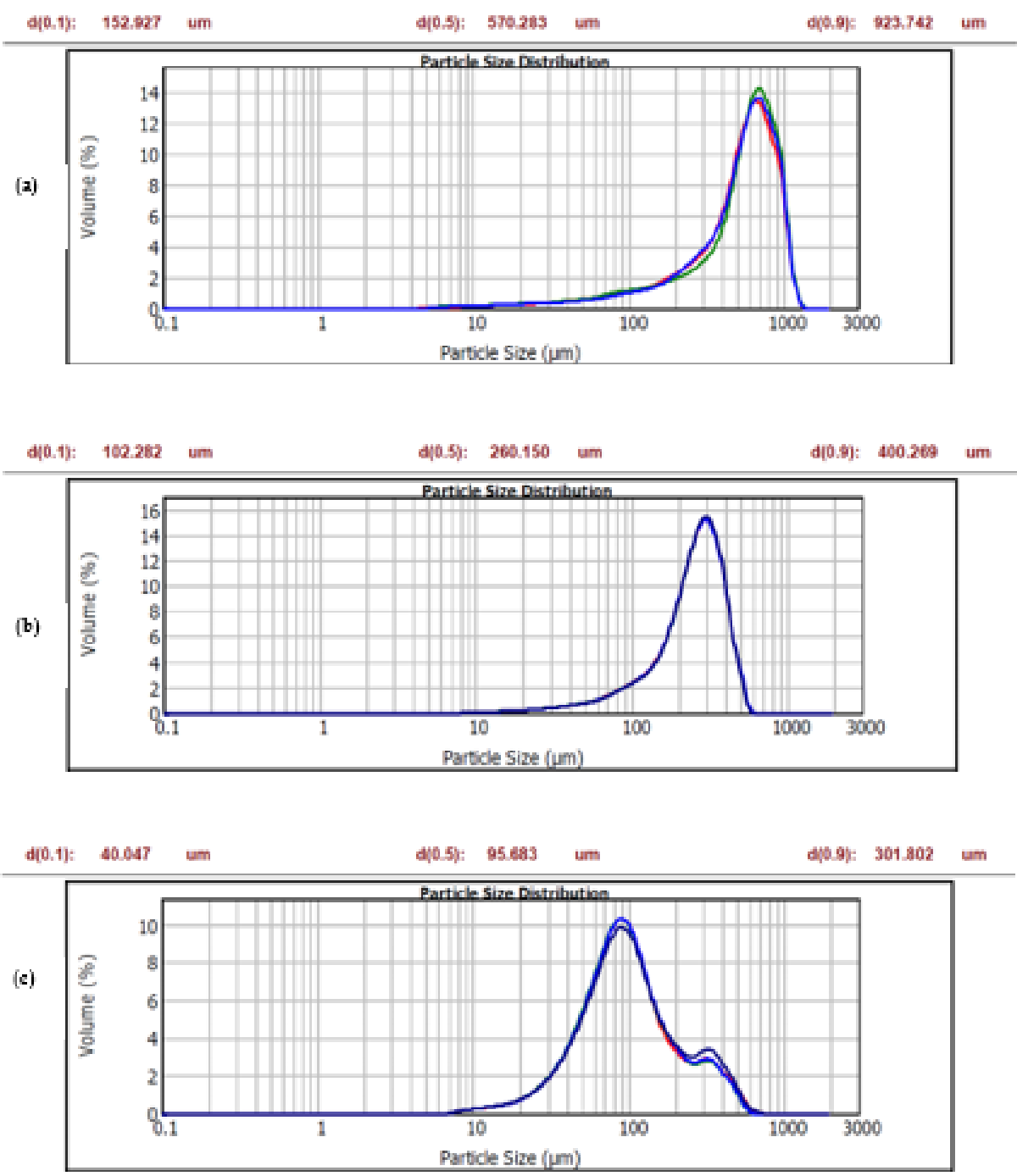

Figure 1. Particle size distribution profiles of prepared granules (a) Metformin $\mathrm{HCl}$ granule used in Test formulation - A; (b) Metformin $\mathrm{HCl}$ granule used in Test formulation - B; (c) Repaglinide granule used in Test formulation - A and Test formulation - B $(n=6)$.

In the present study, ensuring particle size distribution and tapped density specifications (Test formulation - B) develop a surprising effect on content uniformity of repaglinide at finished product. In a further embodiment, the relative standard deviation (RSD\%) of the content uniformity is less than $2.0 \%$ as can be seen in Table 2 for Test formulation - B.

To conclude, Test formulation - B, having satisfactory content uniformity results, was selected for further studies.

\subsection{In vitro and in vivo studies}

\subsubsection{Dissolution studies}

Comparative dissolution profiles of repaglinide and metformin $\mathrm{HCl}$ for Test formulation - $\mathrm{B}$ and reference product in $\mathrm{pH}$ 5.0, which is FDA registered dissolution medium, are shown in Figure 2. According to in vitro dissolution tests between Test formulation - B and Prandimet ${ }^{\circledR} 2 \mathrm{mg}-500 \mathrm{mg}$ Film Coated Tablet (NovoNordisk) conducted at of pH 5.0 citric acid-phosphate buffer, $0.01 \mathrm{~N} \mathrm{HCl}, \mathrm{pH} 6.8$ phosphate buffer mediums, $f 2$ (similarity factor) values for repaglinide are 67.6, 53.9, 54.1 and for metformin 56.7, 61.9, 62.3 respectively. The results obtained confirmed that, for FDA dissolution medium and other two dissolution mediums under comparison, there were similar in vitro dissolution profiles because of that $f 2$ values of all dissolution media are higher than 50 . 


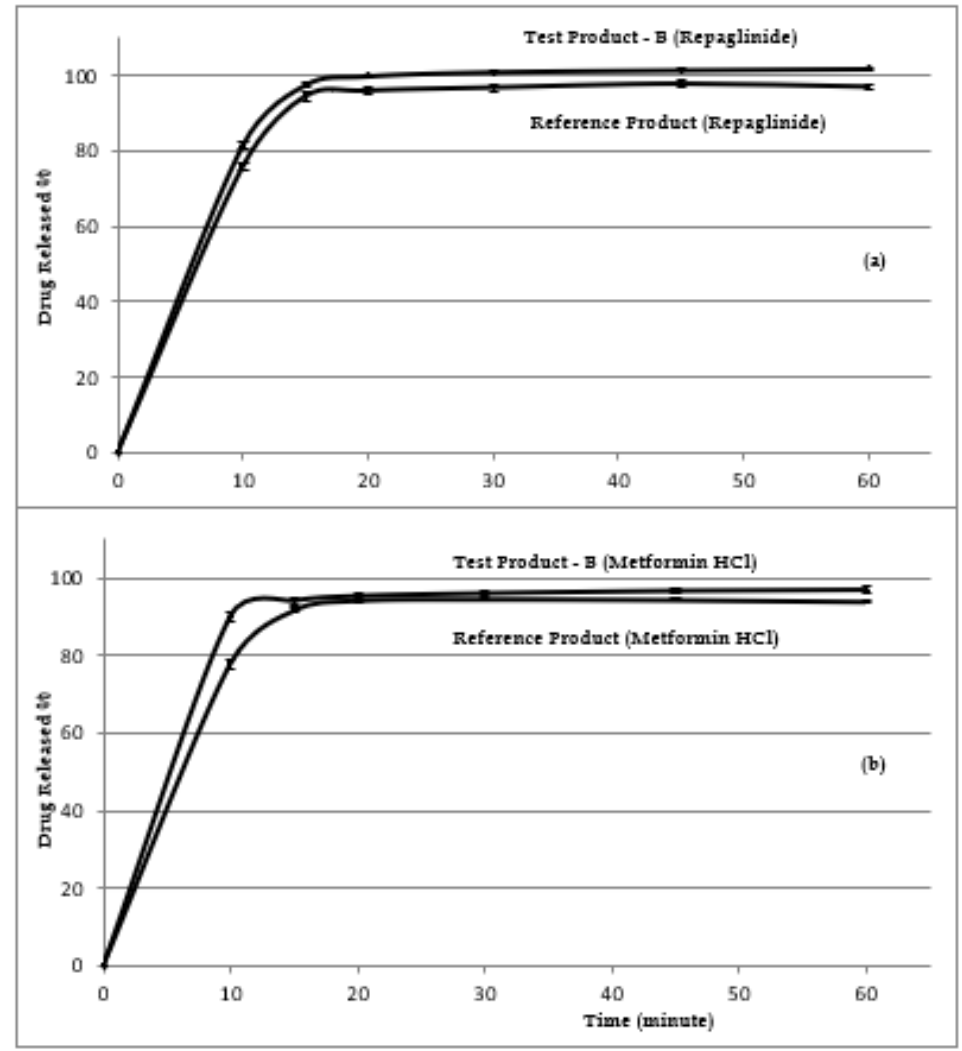

Figure 2. Comparative dissolution profiles of (a) repaglinide and (b) metformin from Test formulation - B vs Reference product, Prandimet ${ }^{\circledR} 2 \mathrm{mg}$ - 500 mg Film Coated Tablets, NovoNordisk, CZ201A. (mean \pm SD, $n=12$; USP App. II (Paddle), dissolution medium: pH 5.0 citric acid-phosphate buffer, $50 \mathrm{rpm}, 900 \mathrm{~mL}$ at $\left.37.0 \pm 0.5^{\circ} \mathrm{C}\right)$.

\subsubsection{Bioequivalence studies}

In vivo study was conducted in healthy human volunteers to asses bioequivalence of test product Repaglinide-Metformin HCl 2mg-500mg Film Coated Tablet (ILKO Pharmaceuticals) with that of reference product Prandimet ${ }^{\circledR}$ (Repaglinide/Metformin $\mathrm{HCl}$ ) 2mg-500mg Film Coated Tablets manufactured by Novo Nordisk Inc., Sweden. Pharmacokinetic parameters under fast conditions of Test product $(\mathrm{T})$ and reference product $(\mathrm{R})$ showed satisfactory results, which are given as;

- For $\mathrm{LnC}_{\max } ; \mathrm{T} / \mathrm{R}$ ratio, $90 \% \mathrm{CI}$ lower, $90 \% \mathrm{CI}$ upper values are $100.51 \%, 88.47 \%, 114.18 \%$ for repaglinide; $110.53 \%, 103.07 \%, 118.53 \%$ for metformin, respectively.

- For LnAUC $0_{0-\mathrm{j}} ; \mathrm{T} / \mathrm{R}$ ratio, 90\% CI lower, 90\% CI upper values are $100.45 \%, 95.78 \%, 105.34 \%$ for repaglinide; $105.22 \%, 101.14 \%, 109.46 \%$ for metformin, respectively.

- For LnAUC -inf; $_{1} \mathrm{~T} / \mathrm{R}$ ratio, $90 \%$ CI lower, 90\% CI upper values are $100.74 \%, 96.00 \%, 105.72 \%$ for repaglinide; $104.87 \%, 100.84 \%, 109.06 \%$ for metformin, respectively.

The composition of the study exhibits bioequivalent to commercially available repaglinide and metformin combination formulation marketed under the trade name Prandimet ${ }^{\circledR} 2 \mathrm{mg}-500 \mathrm{mg}$ Film Coated Tablets.

\subsection{Stability studies}

In a further aspect of the invention, the unit dosage form of formulation according to the invention is physically and chemically stable. Stability of the tablets can be measured at accelerated as well as at long-term storage conditions for periods of several months. Experiments can be performed at different temperatures and humidities. The oral pharmaceutical compositions of the present invention which are prepared according to Test formulation - B were subjected to accelerated stability studies at $40^{\circ} \mathrm{C} \pm 2^{\circ} \mathrm{C} / 75 \% \pm 5$ R.H. (accelerated conditions) and $25^{\circ} \mathrm{C} \pm 2{ }^{\circ} \mathrm{C} / 60 \% \pm 5 \%$ R.H. (long term conditions). Repaglinide - metformin $\mathrm{HCl}$ film coated tablets are stable in terms of appearance, assay and dissolution results at $40^{\circ} \mathrm{C} \pm 2{ }^{\circ} \mathrm{C}, 75 \pm 5 \% \mathrm{RH}$ conditions for 6 months and at $25^{\circ} \mathrm{C} \pm 2{ }^{\circ} \mathrm{C} / 60 \% \pm 5 \%$ RH conditions for 24 months. 


\section{CONCLUSION}

In this work, granules having specific particle size distribution and tapped density specifications were produced in order to provide content uniformity of tablets. Specific particle size distribution and tapped density specifications between metformin $\mathrm{HCl}$ and repaglinide granules were described as (i) particle size distribution $\left(\mathrm{D}_{90}, \mathrm{D}_{50}\right.$ and $\left.\mathrm{D}_{10}\right)$ of metformin $\mathrm{HCl}$ granule should be less than or equal to three times of particle size distribution $\left(\mathrm{D}_{90}, \mathrm{D}_{50}\right.$ and $\left.\mathrm{D}_{10}\right)$ of repaglinide granule; and (ii) tapped density of metformin $\mathrm{HCl}$ granule should be less than or equal to two times of tapped density of repaglinide granule. These granules were mixed to have final mixture and tablets were pressed.

The results show that, ensuring particle size distribution and tapped density specifications of repaglinide and metformin granules highly affect the content uniformity of the repaglinide in drug product. It is observed that, the ensured particle size distribution and tapped density criteria minimize the susceptibility to segregation during the tablet press operation.

To conclude, the study proposed a solution to content uniformity problem of the repaglinide metformin $\mathrm{HCl}$ tablet composition. This procedure can be applied at an industrial level with more effectively than other methods used in the production of repaglinide - metformin tablet. In a further embodiment, there are less mixing and sieving steps with respect to other procedures and in the process, a conventional mixer, which is known as cubic mixer, is used instead of diffusive double cone mixer. The present study gets an edge over literature by lowering the production steps with low energy costs and time efficiency. In the light of these findings, alternative solutions can be developed for different fixed dose combinations having large differences between active substances that can create such content uniformity problems.

\section{MATERIALS AND METHODS}

\subsection{Materials}

Repaglinide (API grade) was obtained from Aurobindho (India); metformin $\mathrm{HCl}$ (API grade) was obtained from Aarti (India). Polyvinylpyrrolidone, N-methylglucamine, microcrystalline cellulose, poloxamer 188, sorbitol, polacrilin potassium, polyethylene glycol 6000 and magnesium stearate were used as inactive ingredients in formulations. Ammonium dihydrogen phosphate, sodium perchlorate monohydrate, and acetonitrile were all purchased from Merck, Germany as analytical grade. Deionized water was supplied in house by Elga System (England).

\subsection{Analytical method and validation studies}

High performance liquid chromatography (HPLC) method was used with a quaternary pump, automatic sampler and diode array detector during analytical method development and validation studies for finished product assay and in vitro dissolution test. ACE C18 250mmx4.6mm and $5 \mu \mathrm{m}$ column was used and chromatographic conditions were set as follows: flow rate: $1.0 \mathrm{~mL} / \mathrm{min}$, injection volume: $10 \mu \mathrm{L}$, column temperature: $40^{\circ} \mathrm{C}$, mobile phase: $5.0 \mathrm{mM}$ ammonium dihydrogen phosphate and $13.0 \mathrm{mM}$ sodium perchlorate monohydrate ( $\mathrm{pH} 1.8$ ) buffer solution mixed with acetonitrile (55:45), wavelength: $240 \mathrm{~nm}$ and analysis time: 12 minutes.

\subsection{Formulation studies}

In this study, repaglinide and metformin granules are manufactured separately with fluidized bed spray granulation method. In this method; Repaglinide, polyvinyl pyrrolidone, N-methylglucamine and poloxamer 188 are solved in ethanol/water mixture. This solution is sprayed onto microcrystalline cellulose to obtain repaglinide granules by spray granulation. Metformin $\mathrm{HCl}$ is granulated with the water solution of sorbitol, polyethylene glycol 6000 and polyvinyl pyrrolidone to obtain metformin $\mathrm{HCl}$ granules by spray granulation method. Particle size distribution and tapped density measurements are applied to prepared granules. According to particle size distribution and tapped density results, granules can be sieved. Obtained repaglinide and metformin granules are mixed and then they are mixed with polacrilin potassium and microcrystalline cellulose. The final blend is obtained by adding magnesium stearate, finally compressed on a high-speed tablet press and tablets are film coated. Unit formula of repaglinide - metformin $\mathrm{HCl} 2 \mathrm{mg}-500 \mathrm{mg}$ film coated tablet is given at Table 4 . 
Table 4. Unit formula of repaglinide - metformin $\mathrm{HCl} 2 \mathrm{mg}-500 \mathrm{mg}$ film coated tablet.

\begin{tabular}{lc}
\hline \multicolumn{1}{c}{ Ingredients } & $\%$ \\
\hline Repaglinide & 0.3 \\
Metformin $\mathrm{HCl}$ & 77.0 \\
Polyvinylpyrrolidone & 4.0 \\
N-methylglucamine & 0.1 \\
Microcrystalline cellulose & 12.5 \\
Poloxamer 188 & 0.1 \\
Sorbitol & 1.0 \\
Polacrilin potassium & 4.0 \\
Polyethylene glycol 6000 & 0.6 \\
Magnesium stearate & 0.4 \\
Film coating & 3.0 \\
\hline
\end{tabular}

\subsection{Content uniformity studies}

\subsubsection{Content uniformity of the final granule mixture}

Repaglinide and metformin granules are manufactured separately with fluidized bed spray granulation method, and then obtained granules are mixed. Content uniformity of the final granule mixture was carried out by withdrawing at least 10 random samples taken from different parts like top, center, bottom and wall locations of the final mixture. Samples selected were tested for repaglinide content using an HPLC assay method mentioned above.

\subsubsection{Content uniformity of the tablets}

Tablets were randomly selected from the beginning, middle and end of each compression run. 10 tablets were tested for their content uniformity using the HPLC assay method mentioned above. Content uniformity test is applied only for repaglinide, not for metformin.

Final product content uniformity had to meet USP $(<905>)$ and EP $(2.9 .6,2.9 .40)$ requirements. Content uniformity of 10 samples has to fall within $90-110 \%$ and RSD not more than $5 \%$ (FDA Guidelines) [16].

\subsection{Particle size distribution}

Particle size distributions were determined using Malvern Mastersizer-2000 (Malvern Instruments, England) with dry dispersion method, single narrow mode, and sample refractive index: 1.50, air vibration rate $30 \%$, obscuration $0.5 \%-5.0 \%$ parameters.

\subsection{Tapped density measurement}

Erweka SVM-102 tapped density tester was used for measuring tapped density of granules. It has been designed to measure tapped volume and tapped density of powders, granules and similar products. It is available for holding one or two glass cylinders and works according USP method.

According to working procedure, a measuring cylinder is weighed on a top pan balance (2 places). Approximately $50 \mathrm{~g}$ powder or granule is introduced into the measuring cylinder, and the weight is recorded. The measuring cylinder containing the granule is attached to a jolting volumeter. The jolting volumeter is set to tap 100 times. During each tap, the measuring cylinder is raised and allowed to fall a set distance. After the 100 taps, the volume of the granule is measured. The tapping is repeated and the new volume measured. The tapping process is continued until the granule will settle to its limits. The tapped density is calculated as the weight of the granule divided by the final tap volume $(\mathrm{g} / \mathrm{mL}$ ). The procedure is performed three times (with new granule each time) for each measured granule, and the mean tapped density calculated from those three final tapped volume values.

\subsection{In vitro and in vivo studies}

\subsubsection{Dissolution studies}

Comparative dissolution studies at three different dissolution media were performed to demonstrate in vitro equivalence between the reference product, Prandimet ${ }^{\circledR} 2 \mathrm{mg}-500 \mathrm{mg}$ Film Coated Tablet (produced by Novo Nordisk Inc., Sweden) and test product to be selected having appropriate content uniformity results. The dissolution tests were carried out with a Distek Evolution 6300 dissolution tester. The used dissolution method registered to FDA is Apparatus II (Paddle), a volume of $900 \mathrm{~mL}$, pH 5.0 citric acid-phosphate buffer 
and $50 \mathrm{rpm}$ at $37.0 \pm 0.5^{\circ} \mathrm{C}$. In addition to FDA registered $\mathrm{pH} 5.0$ media, dissolution studies were carried out at two other dissolution media ( $0.01 \mathrm{~N} \mathrm{HCl}$; $\mathrm{pH} 6.8$ phosphate buffer).

The dissolution profiles were compared; the dissolution profiles obtained were evaluated by similarity factor (f2) (17). According to the EMEA and FDA Guidelines, Dissolution similarity may be determined using the $f 2$ statistic as follows (Eq.1):

$$
f 2=50 \cdot \log \left[\frac{100}{\sqrt{1+\frac{\sum_{t=1}^{n}[R(t)-T(t)]^{2}}{n}}}\right]
$$

In this equation (Eq.1) $f 2$ is the similarity factor, $\mathrm{n}$ is the number of time points, $\mathrm{R}(\mathrm{t})$ is the mean percent reference drug dissolved at time $t$ after initiation of the study; $\mathrm{T}(\mathrm{t})$ is the mean percent test drug dissolved at time $t$ after initiation of the study. For both the reference and test formulations, percent dissolution should be determined. An $f 2$ value between 50 and 100 suggests that the two dissolution profiles are similar [17].

\subsubsection{Bioequivalence studies}

Bioequivalence means the absence of a significant difference in the rate and extent to which the active ingredient or active moiety in pharmaceutical equivalents or pharmaceutical alternatives become available at the site of drug action when administered at the same molar dose under similar conditions in an appropriately designed study [18].

In vivo study was conducted in healthy human volunteers to asses bioequivalence of test product repaglinide - metformin $\mathrm{HCl} 2 \mathrm{mg}-500 \mathrm{mg}$ film coated tablet (ILKO Pharmaceuticals) with that of reference product Prandimet ${ }^{\circledR}$ (Repaglinide/Metformin $\mathrm{HCl}$ ) 2mg-500mg Film Coated Tablets manufactured by Novo Nordisk Inc., Sweden. The study was conducted as an open-label, balanced, randomized, two-treatment, twoperiod, two-sequence, single-dose, two-way crossover in 60 normal, healthy, adult, human subjects under fasting conditions. The study was conducted in accordance with the approved protocol (version no.: 00 dated 26 Sep 2013; approved by IEC on 14 Dec 2013) and in compliance with the requirements of the Ethical guidelines for biomedical research on human participants, ICMR (2006), ICH (Step 5) 'Guidance on Good Clinical Practice', Schedule Y (amended version, 2005) of CDSCO, Turkey Guidelines for Good Clinical Practice, 'Good Laboratory Practice', 'Good Clinical Practices for Clinical Research in India' Guidelines, Good clinical laboratory practice (GCLP), Declaration of Helsinki (Brazil 2013) and applicable regulatory requirements.

\subsection{Stability studies}

The selected formulation having satisfactory content uniformity results was investigated according to the requirements of the ICH stability guideline [19]. For this purpose, tablets were kept in stability cabinets at $40^{\circ} \mathrm{C} \pm 2^{\circ} \mathrm{C} / 75 \% \pm 5$ R.H. (accelerated conditions) and $25^{\circ} \mathrm{C} \pm 2^{\circ} \mathrm{C} / 60 \% \pm 5 \%$ R.H. (long term conditions). At determined time intervals, the test products were evaluated from the perspective of specifications such as appearance, assay and dissolution tests.

Acknowledgements: This study was supported by ILKO Pharmaceuticals. The authors thank ILKO Pharmaceuticals R\&D Center colleagues for their contributions to this research.

Author contributions: Concept - O.P., GP.G., B.KÖ., A.AD.; Design - O.P., GP.G., B.KÖ., A.AD.; Supervision - O.P., A.AD.; Resources - O.P., GP.G., B.KÖ., A.AD.; Materials - O.P., GP.G., B.KÖ., A.AD.; Data Collection and/or Processing - O.P., GP.G., B.KÖ., A.AD.; Analysis and/or Interpretation - O.P., GP.G., B.KÖ., A.AD.; Literature Search - O.P., GP.G., B.KÖ., N.S., A.AD.; Writing - N.S.; Critical Reviews - O.P., GP.G., B.KÖ., N.S., A.AD.

Conflict of interest statement: The authors declared no conflict of interest.

Ethics committee approval: The study was conducted in accordance with the approved protocol (version no.: 00 dated 26 Sep 2013; approved by IEC on 14 Dec 2013) and in compliance with the requirements of the Ethical guidelines for biomedical research on human participants, ICMR (2006), ICH (Step 5) 'Guidance on Good Clinical Practice', Schedule Y (amended version, 2005) of CDSCO, Turkey Guidelines for Good Clinical Practice, 'Good Laboratory Practice', 'Good Clinical Practices for Clinical Research in India' Guidelines, Good clinical laboratory practice (GCLP), Declaration of Helsinki (Brazil 2013) and applicable regulatory requirements. 


\section{REFERENCES}

[1] IDF, International Diabetes Federation. About Diabetes. What is diabetes? https://www.idf.org/ aboutdiabetes/what-is-diabetes.html (accessed on 22 June 2020).

[2] Glucophage ${ }^{\circledR}$ (Metformin hydrochloride) Tablet product labelling. USA: Bristol-Myers Squibb. https://www.accessdata.fda.gov/drugsatfda_docs/label/2017/020357s037s039,021202s021s023lbl.pdf (accessed on 10 February 2020).

[3] Raskin P. Oral combination therapy: repaglinide plus metformin for treatment of type 2 diabetes. Diabetes Obes Metab. 2008; 10(12): 1167-1177. [CrossRef]

[4] Prandin ${ }^{\circledR}$ (Repaglinide) tablet product labeling. (2012). Germany: Novo Nordisk. https://www.accessdata.fda.gov/drugsatfda_docs/label/ 2012/020741s040lbl.pdf

[5] Bell DSH. Combine and conquer: advantages and disadvantages of fixed-dose combination therapy. Diabetes Obes Metab. 2013; 15(4): 291-300. [CrossRef]

[6] Moses R, Slobodniuk R, Boyages S, Colagiuri S, Kidson W, Carter J, Donnelly T, Moffitt P, Hopkins H. Effect of repaglinide addition to metformin monotherapy on glycemic control in patients with type 2 diabetes. Diabetes Care. 1999; 22(1): 119-124. [CrossRef]

[7] Moses R. Repaglinide in combination therapy with metformin in Type 2 diabetes. Exp Clin Endocrinol Diabetes. 1999; 107(04): 136-139. [CrossRef]

[8] Moses RG. Repaglinide/metformin fixed-dose combination to improve glycemic control in patients with type 2 diabetes: an update. Diabetes Metab Syndr Obes. 2010; 3: 145. [CrossRef]

[9] Prandimet ${ }^{\circledR}$ (repaglinide and metformin $\mathrm{HCl}$ ) product labeling. US: Novo Nordisk. https://www.accessdata.fda.gov/drugsatfda_docs/ label/2012/022386s007lbl.pdf (accessed on 10 February 2020).

[10] Block LC, Schmeling LO, Couto AG, Segatto MA, Tagliari MP, Bresolin TM, Mourao S. Effect of binders on 500mg metformin hydrochloride tablets produced by wet granulation. Rev Ciênc Farm Básica Apl. 2009; 30(2): 145-152.

[11] Zhaolu Z, Tianzhi Y, Yanan Z, Nannan G, Donglei L, Pingtian D. A simple method to improve the dissolution of repaglinide and exploration of its mechanism. Asian J Pharm Sci. 2014; 9(4): 218-225. [CrossRef]

[12] Kukkar V, Anand V, Kataria M, Gera M, Choudhury PK. Mixing and formulation of low dose drugs: Underlying problems and solutions. Thai J Pharm Sci. 2008; 32(3-4): 43-58.

[13] Ramírez-Aragón C, Alba-Elías F, González-Marcos A, Ordieres-Meré J. Segregation in the tank of a rotary tablet press machine using experimental and discrete element methods. Powder Technol. 2018; 328: 452-469. [CrossRef]

[14] Rohrs BR, Amidon GE, Meury RH, Secreast PJ, King HM, Skoug CJ. Particle size limits to meet USP content uniformity criteria for tablets and capsules. J Pharm Sci. 2006; 95(5): 1049-1059. [CrossRef]

[15] Zhang Y, Johnson KC. Effect of drug particle size on content uniformity of low-dose solid dosage forms. Int J Pharm. 1997; 154(2): 179-183. [CrossRef]

[16] Muselík J, Franc A, Doležel P, Goněc R, Krondlová A, Lukášová I. Influence of process parameters on content uniformity of a low dose active pharmaceutical ingredient in a tablet formulation according to GMP. Acta Pharm. 2014; 64(3): 355-367. [CrossRef]

[17] EMEA, European Medicines Agency. Guideline on the investigation of bioequivalence. https://www.ema.europa.eu/en/documents/scientific-guideline/guideline-investigation-bioequivalencerev1_en.pdf (accessed on 03 March 2020)

[18] Chow SC. Bioavailability and bioequivalence in drug development. Wiley Interdiscip Rev Comput Stat. 2014; 6(4): 304-312. [CrossRef]

[19] EMEA, European Medicines Agency. ICH Topic Q1A(R2) Stability Testing of New Drug Substances and Products. https:// www.ema.europa.eu/en/documents/scientific-guideline/ich-q-1-r2-stability-testing-new-drugsubstances-products-step-5_en.pdf (accessed on 30 January 2020) 